\title{
La biblioteca de la poetisa gaditana sóror María Gertrudis de la Cruz Hore (1742-1801)
}

Frédérique Morand Universidad París VIII

CES.XVIII, núm. 17 (2007), págs. 249-274. 
Resumen: Este artículo desvela algunas de las lecturas conventuales y preocupaciones de la poetisa e ilustrada sóror María Gertrudis de la Cruz Hore (17421801) profesa en el monasterio de Concepcionistas Calzadas de Cádiz a finales del setecientos. A partir de la lista de sus libros recogidos en su inventario post mórtem, intenté adentrarme en cada uno de estos títulos. Me propuse, en la medida de lo posible, desenmarañar dicha lista de libros, reubicar a los autores, descifrar los títulos enigmáticos, y leer las obras que María Gertrudis poseía en su celda, para hacerme mayor idea de sus intereses. El elemento de comparación, consustancial a cualquier estudio, adquiría aquí un fácil acceso por los trabajos realizados sobre bibliotecas de otros ilustrados, en este caso, principalmente gaditanos. Por otra parte, la labor de ordenación y consulta de los más de doscientos libros actualmente conservados en la biblioteca conventual ofrecía una visión si no más precisa, más acorde con su universo claustral. Por su peculiar camino de vida y tardío ingreso en el monjio, el estudio de la biblioteca de esta gaditana ilustre brindaba la oportunidad de conocer no sólo el estante de una religiosa concepcionista a finales del setecientos, sino el de una ilustrada en clausura, aunque la muestra oficial fuera escasa. Por último, algunos de sus textos permitían vislumbrar cómo utilizó y transformó ciertas de sus lecturas en creaciones propias.

Palabras clave: Bibliotecas. Concepcionista. Escritoras. Cádiz. 
A finales de 1999, la doctora Aurora Guzmán se preguntó qué se sabía de las lecturas conventuales, qué leían las monjas y qué tipo de religiosa era más proclive a ser poeta ${ }^{1}$. Con anterioridad, el profesor Arturo Morgado, en su artículo sobre «Bibliotecas clericales en el Cádiz del siglo XVIII», afirmó que los inventarios post mórtem eran muy escasos en la Época Moderna en Cádiz².

Ante estas incógnitas, en posesión del inventario post mórtem de la religiosa y poetisa gaditana de finales del siglo xvIII, María Gertrudis de la Cruz Hore, me pareció interesante comentar algo de las obras que poseía esta erudita monja, fuente inesperada para acercarse a las inclinaciones de la poetisa, además de explicar la construcción de algunas de sus creaciones y desvelar, quizás, algo de las lecturas conventuales de las religiosas de finales del setecientos ${ }^{3}$. Ese inventario post mórtem, documento de carácter oficial, no podía ser el fiel índice de todas sus lecturas a lo largo de su monacato, como bien es sabido, pero sí podía dar mayor idea de sus preocupaciones intelectuales, así como de sus lecturas, al menos, en su celda. Una oportunidad única para ilustrar, con datos históricos, algunos versos manuscritos de la gaditana con los que Mónica Bolufer eligió empezar uno de sus artículos, en el que incentivaba a la comunidad científica a continuar y ampliar el estudio de las bibliotecas femeninas en España:

1 Aurora Domínguez Guzmán, «De monjas y de poesía de ocasión en la España del seiscientos», en Romper el espejo, la mujer y la transgresión de códigos literarios en la literatura española: escritura, lectura, textos (1001/2000), María José Porro Herrera (ed.), Córdoba, 2001, págs. 46-47.

2 Arturo Morgado García, «Bibliotecas clericales en el Cádiz del siglo XviII», en Hispania Sacra, 87, vol. XLIII, 1991, págs. 343-344.

3 Vid. Constance Suldivan, «"Dinos, dinos quién eres": The Poetic Identity of María Gertrudis Hore (1742-1801)», en Pen and Peruke: Spanish Literature of the Eighteenth Century, Monroe Hafter (ed.), Michigan Romance Studies, XII, 1992, págs. 153-183. De la misma autora: «Las escritoras del siglo XVIII», en Breve historia feminista de la literatura española (en lengua castellana), IV. La literatura escrita por mujer (de la Edad Media al s. XVIII), Zavala Iris M. (coord.), Barcelona, editorial Anthropos, 1997, págs. 305-330. Elisabeth Franklin LEwis, «Mythical Mystic or "Monja Romántica"?: The Poetry of María Gertrudis Hore», en Dieciocho, 16, 1-2, 1993, págs. 95-109. De la misma autora: Women Writers in the Spanish Enlightenment. The Pursuit of Happiness, Ashgate Publishers, England and Burlington, 2004, págs. 61-95. Pierre L. UlLman, «Estructura Rococó y sensibilidad prerromántica de El Nido de María Gertrudis Hore», en Salina, núm. 14, noviembre 2000, págs. 101-106. Mbol NANG, «La verticalidad espiritual en la poesía de doña María Gertrudis de Hore», en Cuadernos para la Investigación de la Literatura Hispánica, núm. 25, 2000, págs. 63-70. 
A la labor dedico algunos ratos,

Otros en la lectura me divierto,

Y la pluma me ponen en la mano

Gusto, y obligación al mismo tiempo ${ }^{4}$.

He aquí la lista, fechada a 11 de agosto de 1801, de los libros recogidos en el inventario post mórtem de la que escribió este poema endecasílabo a sus amigas:

\section{Un Estante Con los Libros Siguientes}

Dos juegos de Breviarios, un Diurno, y Octavarios

El Diccionario de Moreri, y uno de Lengua Castellana

Año Cristiano y la M.e Ágreda no completos

P.e Calino y la Religiosa Instruida

Introducción a la Vida Devota por S.n Fran.co de Sales

Triunfo de la Religión y la fundación de las Monjas de Mula

Varios Libros devotos

El esquema de este inventario, al menos en materia de libros, seguía el trazado por Arturo Morgado al estudiar las bibliotecas de clérigos gaditanos durante el siglo XVIII, el de Christian Peligry al catalogar el inventario del librero madrileño Sebastián de Robles en el siglo XVII, así como el de José Luis Barrio cuando afirmó que «el escribiente que se encargaba de transcribir las indicaciones [...] omitía a menudo el apellido de los autores, el lugar y la fecha de impresión, y desfiguraba no pocas veces el mismo título de las obras» ${ }^{5}$.

A primera vista, esta lista de libros podría parecernos escueta. Principalmente compuesta por, como era de suponer, obras y revistas religiosas, además de los diccionarios históricos y de lengua, difícilmente estos once títulos podían formar una extensa biblioteca. Era una biblioteca pequeña (menos de cincuenta títulos) la de sor Gertrudis; no obstante, si un elevado número de libros no indicaba forzosamente un interés por la cultura ${ }^{6}$, un número corto de obras tampoco

\footnotetext{
4 Versos manuscritos de María Gertrudis Hore. «Endecasílabos a sus amigas». Citado por Mónica Bolufer Peruga, «Mujeres de letras: lectoras y escritoras en los siglos modernos», en Relaciones de género, sociedad y cultura en el ámbito mediterráneo, Málaga, 2005 (en prensa).

5 En la tienda del difunto había 1369 volúmenes, principalmente obras de lingüística y de carácter religioso, clásicos latinos, obras de física y de medicina. Christian PéLigrY, «El inventario de Sebastián de Robles, librero madrileño del siglo XVII», en Cuadernos Bibliográficos, núm. 32, Madrid, 1975, págs. 181-188. José Luis BARrio MoYa, «La gran biblioteca de la dama manchega doña María del Padre Eterno Varona y Rozas, marquesa de Añavete (1755)», en Cuadernos de Estudios Manchegos, núm. 19, 1989, págs. 139-140.

6 Máxime Chevalier, Lectura y lectores en la España del XVI y XVII, Madrid, Turner, 1976, págs. 41-44.
} 
marcaba un desinterés por el conocimiento. En efecto, no estábamos ante la importante colección de libros reunida por la duquesa de Osuna y sus administradores ${ }^{7}$, tampoco ante la biblioteca de la duquesa de Liria, con su 327 títulos y 1217 volúmenes en latín, francés e inglés ${ }^{8}$, o la de María del Padre Eterno Varona y Rozas, Marquesa de Añavete con sus 488 títulos y 837 tomos ${ }^{9}$. Empero, ¿leyeron estas damas todos estos volúmenes?

Como sugirió la profesora López-Cordón:

El estudio de las lecturas o de los textos impresos, que constituyen el horizonte intelectual de una generación, o de un determinado grupo social, no puede quedar circunscrito a los títulos de que quedan constancia en los inventarios de las bibliotecas particulares ${ }^{10}$.

Por tanto, intentemos adentrarnos algo más en cada uno de estos títulos porque, como el inventario de la Marquesa de Añavete lo demostraba, el número de títulos no solía corresponder con la proporción de libros en el estante. Por otra parte, siendo religiosa de clausura, era de suponer que frecuentó la biblioteca conventual, además de tener libros propios, como lo hizo en el siglo Josefa Amar y Borbón al buscar referencias en la Biblioteca Real y en la de San Ildefonso en Zaragoza $^{11}$, aunque sor Gertrudis lo hiciera en mucho menor medida ${ }^{12}$.

Algunos títulos descubrían ya el camino de excepción de esta tardía monja educada en el seno de una familia de comerciantes irlandeses de renombre (el Diccionario de Moreri y de Lengua Castellana); otros, propios de su condición de profesa, eran lecturas obligadas para una novicia (La Religiosa Instruida...) y lectura habitual en círculos de ilustrados (Año Cristiano...). A mi juicio, estos once títulos, además de «Varios Libros devotos» (¿cuáles fueron y cuántos había?, ¿cinco, diez, veinte?) reflejaban, pese a su aparente escasez, el camino de excep-

7 Condesa de Yebes, La Condesa de Benavente. Una vida en unas cartas, Madrid, Espasa Calpe, 1955, págs. 191-196.

8 AHn, Inquisición, leg. 2.538, caja 1, expág. 1. Citado por Elizabel Larriba, Le public de la presse en Espagne à la fin du XVIII siècle (1781-1808), París, Honoré Champion, 1998, pág. 166.

9 José Luis Barrio Moya, art. cit., págs. 135-157.

10 María Victoria LóPEz-CoRdón, «Traducciones y traductoras en la España de finales del siglo XVIII», en G. NiELfa (ed.), Entre la marginación y el desarrollo. Mujeres y hombres en la Historia, Madrid, Edición del Orto, Instituto de Investigaciones Feministas de la UCM, 1996, págs. 89-90.

11 Vid. María Victoria López-Cordón, Condición femenina y razón ilustrada: Josefa Amar y Borbón, Prensas Universitarias de Zaragoza e Instituto Aragonés de la Mujer, 2005.

12 En la biblioteca conventual, tras sufrir numerosos asaltos y robos a lo largo de los siglos, principalmente en el siglo xx e incluso muy avanzada la centuria, se conservaban aproximadamente doscientos volúmenes, de los cuales al menos quince eran del siglo XVII con tapa de pergamino, contra ciento dos impresos publicados en el siglo XVIII, de los cuales diecinueve eran libros en $4 .^{\circ}$ con tapa de cuero. Algunos no tenían fecha y los demás volúmenes fueron publicados principalmente en el siglo XIX. 
ción de esta dama de la alta sociedad gaditana, cuyas lecturas, en su mayoría, eran compartidas por ilustrados, entre ellos el gaditano Vicente Pulciani ${ }^{13}$. Aunque imprecisa, esta lista permitía tener una idea más concreta de sus inquietudes e intereses una vez ingresada en el monasterio y, quizás, pueda servir para establecer algunas pautas de lectura para las religiosas de finales de la centuria.

María Gertrudis Hore fue monja casada, culta, inteligente, ingresada de forma algo extraña y tardía, tras ser madre, en el monasterio de Santa María ${ }^{14}$; traducía latín e italiano, y tenía nociones de francés en una época en la que sólo unas cuantas mujeres disfrutaban de una educación selecta, aunque todas las profesas sabían leer. Me pregunté si esta lista se podría parecer a los anaqueles de una ilustrada en el siglo: las lecturas de carácter histórico, moral y religioso eran lecturas habituales entre los curiosos, además de, por cierto, libros de derecho, de ciencia y arte, de medicina, de filosofía, astronomía, novelas, literatura sentimental, obras sobre educación, divulgación médica, etcétera, que había de poseer todo buen ilustrado en su biblioteca ${ }^{15}$. Sin embargo, ninguna de estas obras aparecía en el inventario post mórtem de la monja ilustrada.

\section{Entre documentación oficial y «realidad»}

La total ausencia de estos libros, o su aparente ausencia en el espacio monacal, se podía explicar de mil maneras. En primer lugar, por su estatuto de religiosa, María Gertrudis había de leer textos en armonía con los votos pronunciados antes que otros poco aconsejables. Pese a ello, y no sólo su poesía permitía afirmarlo sino su primer biógrafo, leyó varias de estas obras imprescindibles en toda buena educación, al menos antes de ingresar en clausura: «Era hermosísima, de mucha gracia y viveza, de un talento despejadísimo, y lo empleaba de continuo leyendo obras selectas y eruditas» ${ }^{16}$.

Adornó su celda con recuerdos de su vida anterior (cómoda, papeleras de caoba, guarda ropa...) cuando era seglar, casada, rica, adulada y rodeada de

\footnotetext{
13 María Nélida García Fernández, Burguesía y toga en el Cádiz del siglo XVIII. Vicente Pulciani y su biblioteca ilustrada, Servicio de Publicaciones de la Universidad de Cádiz, 1999.

${ }_{14}$ Frédérique Morand, «¿Qué sabemos del hijo de la monja sor María Gertrudis de la Cruz Hore (1742-1801) y de su esposo, Esteban Fleming?», en Dieciocho, vol. 28 (primavera 2005), págs. 141-158.

15 Livre et lecture en Espagne et en France sous l'Ancien Régime, Colloque de la Casa de Velázquez los 17, 18, 19 de noviembre de 1980, París, ed. ADPF, 1981.

16 N. M. Cambiaso, Memorias para la biografía y para la bibliografía de la isla de Cádiz, Madrid, Imprenta de D. León Amarita, 1830, t. II, pág. 72; ed. Caja de Ahorro, preparada por Ramón Corzo Sánchez y Margarita Toscano San Gil, Cádiz, 1986, reed. de los dos primeros vols. impresos en Madrid en 1829, 1. ${ }^{\text {e ed. }}$ del tercer vol. inédito, pág. 213.
} 
sirvientes y esclava ${ }^{17}$. Por tanto, era de suponer que llevase también algunos libros al convento, dado que su selecta formación era notoria mucho antes de que vistiera el velo ${ }^{18}$. Me resultaba difícil pensar que la Hija del Sol, como la apodaron sus coetáneos por su belleza y su ilustración, en la opulenta Cádiz, se privase durante más de dos décadas de todas las novedades en materia de astronomía, a la que era particularmente aficionada, de música, conociendo su formación, o de medicina, mientras ejerció de acompañante de médico en la clausura en la década de 1790. El cuidado de la salud fue un verdadero descubrimiento del siglo XVIII y los impresos sobre cómo conservarla, prevenir los achaques y combatir las dolencias, de lectura casi obligatoria para el público culto ${ }^{19}$.

Compuso un largo poema endecasílabo empezando por una frase en latín extraída de las Metamorfosis de Ovidio ${ }^{20}$, quince libros de lectura obligatoria entre los ilustrados. En la misma época, traducía poemas del italiano ${ }^{21}$ y afirmaba a su amiga Gerarda, en una carta en versos conservada en la Biblioteca Menéndez Pelayo, dejarse llevar por la filosofía del inglés Edward Young, por la IV Noche. El profesor Sebold confirmaba esta lectura, la de las Nights Thoughts, a partir de la traducción francesa de Le Tourneur ${ }^{22}$.
¿Mas dónde voy?... perdona mis discursos,
mi distracción perdona, amiga mía,
que del Inglés filósofo ${ }^{23}$ la cuarta
noche arrebató mi fantasía ${ }^{24}$.

El francés, idioma que formaba parte del bagaje propio de una educación de elite en la Europa del siglo XVIII, no aparecía en ninguno de los títulos reco-

17 ACSM, Los objetos personales de María Gertrudis, ajuar de celda.

18 La investigación llevada a cabo permitió adelantar en veinte años la fecha de su primera publicación respecto a los conocimientos actuales; no publicó por vez primera en 1787, cuando tenía cuarenta y cinco años y era monja de clausura, sino cuando era todavía una seglar, con veintiséis años. Vid. Frédérique Morand, Una poetisa en busca de libertad. María Gertrudis Hore y Ley (1742-1801), Servicio de Publicaciones de la Diputación de Cádiz, 2007.

19 V. M. LóPEZ-CoRdón, «Traducciones y traductoras en la España de finales del siglo XVIII», art. cit., págs. 94-96.

20 «Augere pudor, verum que fides que in quorum subiere locum, fraudes que, doli que in vidie que et vis et amor sceleratus habendi», Ovid., Metam., BNM, ms. 4061, ff. 251-254b.

21 Soneto: «A Voltaire sobre el estado actual de la Francia», ibid., f. 255.

22 Russell P. Sebold, «Temas y técnica de la lírica neoclásica», en Guillermo Carnero (coord.), Historia de la literatura española, siglo XVIII (I), Madrid, Espasa Calpe, 1995, págs. 188-189.

23 «Alude a "Las Noches", de Young, muy admiradas en aquel tiempo". Precisión hecha por Cueto en el manuscrito de Santander. Vid. Leopoldo Augusto Cueto, Poetas líricos del siglo XVIII (ed. orig. 1869/1875), BAE, t. III, 67, Madrid, Atlas, 1953, págs. 553-559.

24 BMP, D 119, ff. 6a/d. Este poema fue trascrito por Martín F. de Navarrete. 
gidos. Ni el francés, ni otro idioma como hubiera podido ser el italiano o el latín, sabiendo que la poetisa manejaba varios. Los elogios del Censor Mensual en el Diario de Madrid de 1795, seudónimo detrás del que se escondía el poeta agustino fray Juan Fernández de Rojas, no permitía dudar de la selecta educación de esta concepcionista. Más conocido como Liseno ${ }^{25}$, y miembro del Parnaso Salmantino desde su comienzo, el crítico tenía constancia de la existencia de esa gaditana: «su instrucción en varias lenguas, su erudición escogida, su buen gusto e ingenio, juntamente con sus prendas personales, la han adquirido la admiración de cuantos la han tratado» ${ }^{26}$.

¿Cómo creer que se privase de la lectura de sus contemporáneos, de las poesías de Margarita Hickey, Jovellanos, Meléndez Valdés, de los versos de Jorge Manrique, de las obras de Góngora o las de fray Luis de León, tras leer sus poemas publicados en prensa en la década de 1790? ${ }^{27}$. Quizás sor Victoria Bosichi, la que recogió esta lista de libros ${ }^{28}$, prefirió traducir los títulos. A no ser que la Hija del Sol conservase sólo algún tiempo estas obras en su celda, el tiempo de leerlas.

Podíamos extrañarnos de la ausencia de un Diccionario de Latín-Español en su celda, sabiendo que su mayor éxito fue la traducción y glosa del Stabat Mater dolorosa publicado en Cádiz a finales de la centuria, en Barcelona por el Beato Diego, en la revista el Año Cristiano en 1863, así como en 1921, en Sevilla, en la revista franciscana $\mathrm{La}$ Voz de San Antonio ${ }^{29}$. Es difícil pensar que todas sus lecturas fueron inscritas en su inventario post mórtem. Sin embargo, me pareció interesante descubrir y estudiar más detenidamente parte de esta lista oficial

25 Su participación en el periódico como crítico empezó el 4 de enero de 1795 hasta 1799 con una sola ausencia por indisposición en marzo, abril y mayo de 1797. María Rosario Barabino Macia, Fray Juan Fernández de Rojas: su obra y significación en el siglo XVIII, Madrid, tesis doctoral, Servicio de Reproducción de la Universidad Complutense, 1981, págs. 379, 396-397 y 429.

${ }_{26}$ Diario de Madrid, «Juicio de los Diarios del mes de Mayo», lunes 8 de junio de 1795, pág. 651. Citado por Manuel SERrano y Sanz, art. cit., pág. 529, nota 1.

27 Vid. María del Pilar Zorrozua Santisteban, Escritoras de la Ilustración española (1759-1808), Bilbao, Departamento de Publicaciones Universidad de Deusto, 1999, tesis doctoral micro fichada. Frédérique Morand, «Sor María Gertrudis de la Cruz Hore (1742-1801) y los elogios de la crítica o el orgullo de ser poetisa», en $2 .^{\circ}$ t. de la colección Imagen y Palabra de Mujer, Valladolid, ed. Fundación Instituto Castellano Leonés de la Lengua, 2006 (en prensa).

28 La grafía de esta monja me era conocida: fue clavera de 1799 a 1824 . Era natural de Cádiz, hija de Rodolfo Bosichi y de Juana Crisóstomo Moyano difunta. Profesó el 3 de septiembre de 1786 con dieciséis años y su firma desvelaba ya la educación recibida; había vivido desde los once años, probablemente por ser huérfana de madre, como seglar en el convento. Por tanto, había recibido educación en el monasterio, quizás, ayudada de la madre Cruz. ACSM, Libro de entradas y profesiones de religiosas de Santa María formado en el año de 1734, ff. 153 y 158. Libro manuscrito de 1718 a 1872 sobre elección de oficios, s. f.

29 Frédérique Morand, «El Stabat Mater glosado y traducido por sor María Gertrudis de la Cruz Hore a fines del siglo XVIII», en Hispania Sacra, núm. 118, julio-diciembre de 2006, págs. 579-607. 
en la que se recogía ora los títulos, ora los autores y, con suerte, dos obras con título y autor ${ }^{30}$.

\section{Estudio pormenorizado del inventario post mortem. El Diccionario de Moreri, y uno de Lengua Castellana}

Cuando sugerí que pudo entrar en la clausura con algunos libros, pensaba muy particularmente en el Gran Diccionario Histórico de Luis Moreri de 1674, una obra en diez volúmenes de tamaño considerable y de referencia entre los ilustrados, particularmente en Cádiz. El gaditano Sebastián Martínez poseía en su biblioteca esta obra editada en francés y clasificada entre las más caras del siglo XVIII (se hicieron dieciocho ediciones) $)^{31}$. Otro gaditano de la época, Vicente Pulciani, en su biblioteca (907 títulos con 2011 volúmenes), tuvo hasta tres ejemplares de esta obra, el original en francés publicado en Lyon en 1674, y dos ejemplares de la primera edición española de $1753^{32}$. La labor de traducción de esa edición duró más de veinte años y fue emprendida por el gaditano Joseph de Miravel y Casadevante, vecino del Puerto de Santa María. Al leer la introducción, me llamó la atención la proposición de Joseph de Miravel: ofrecer el Diccionario de la Lengua Castellana al comprador del Diccionario de Moreri; porque en el inventario de sor Gertrudis estaba escrito: «El Diccionario de Moreri y uno de Lengua Castellana». Podía suponer que la Hija del Sol aprovechó la promoción y que, tal vez, estuviera en posesión de esta edición de $1753^{33}$. Con mayor motivo, sabiendo que fue, al menos geográficamente, cercana al traductor. Esta obra de consulta abarcaba todo tipo de temas de interés para la historia sagrada y profana, la geografía, la arquitectura, la crítica, las genealogías, los papas, los autores antiguos y modernos, las órdenes religiosas y militares, etcétera, en fin, constituía un auténtico tesoro de sabiduría. Su elevado precio, 1.110 rs de vn, recordaba el nivel y el estatus social de sor María de la Cruz, incluso en el monasterio, así como su interés por la civilización y el conocimiento a lo largo de su existencia, fiel a la visión ilustrada favorable a un aprendizaje durante toda la vida.

30 ACSM, Inventario post mórtem de María Gertrudis de la Cruz Hore. Bartolomé Bennasar, «Los inventarios post mórtem y la historia de las mentalidades», en Actas del II Coloquio de Metodología Aplicada. La documentación notarial y la historia, Santiago de Compostela, 1984, pág. 141.

31 A. García-Barquero González, Libro y cultura burguesa en Cádiz: La biblioteca de Sebastián Martínez, Cádiz, Fundación Municipal de Cultura, 1988, págs. 45-46 y 49.

32 María Nélida García Fernández, loc. cit., págs. 81 y 212. El Diccionario de Moreri formaba parte de la biblioteca de la condesa de Añavete. José Luis Barrio MoYa, art. cit., págs. 140-141.

33 Luis Moreri, El Gran Diccionario Histórico o Miscelánea curiosa de la Historia Sagrada y profana, por don Joseph de Miravel y Casadevante, París, ed. por los Libreros privilegiados o los Hermanos de Tournes, 1753, t. I, introducción. 


\section{Dos juegos de breviarios, un diurno y octavarios}

Si volvemos a los primeros libros de la lista, teníamos dos juegos de breviarios.

El origen y la función de este libro, uno de los cuatro de la Iglesia, era las Oraciones del Oficio Divino y, principalmente, del Oficio de la Noche, es decir de los Maitines. No era ningún libro de lectura (Evangelio...), tampoco de canto (antifonario o gradual), ni de rituales, sino de rezo, en perfecta adecuación con su estatuto de religiosa de coro, aunque lo usaban también los seglares que faltaban a misa: recogía, para cada día de la semana, cada fiesta, los siete rezos ${ }^{34}$.

Si consideramos las fechas de edición del breviario y misal romanos, respectivamente 1568 y 1570, era de subrayar que la doctora María Matesanz, durante su trabajo de tesis sobre una traducción parcial de la Biblia, tuvo conocimiento de la redacción de un breviario para la Orden de la Inmaculada Concepción (OIC) publicado en Toledo, en 1508 (libro en 8. . de 146 págs.), o sea, mucho antes de que los papas se preocupasen por ello. Desgraciadamente, la primera edición no apareció en la casa madre de la Orden, en Toledo. Su título en latín: Brevarium secundum usum ordinis Concetionis Beatae Virginia Mariae. La doctora localizó una edición posterior con fecha de 1551, todavía anterior a los decretos oficiales: comenzaba por algunos salmos e himnos para el rezo, y suponía que la segunda edición se publicó en Alcalá de Henares ${ }^{35}$.

Convenía aludir a la situación histórica y al pontificado de Julio II (1503-1513), y preguntarse por qué las Concepcionistas tuvieron breviario tan temprano (1508), e incluso antes de formar una orden, antes de tener regla propia en 1511. Probablemente cercano a algunos, o algunas, partidarios de la futura nueva orden, el pontífice llevó a cabo la consecución de ese Breviario avant la lettre. Poco después, durante el quinto concilio de Latrán (1512-1517), aprovechó para reconsiderar la utilidad del breviario. Quizás fuera preámbulo a su afirmación conciliar a la vez que muestra de interés hacia el empeño de sus seguidoras $^{36}$.

34 Laudes que se rezaban al salir el sol. Prima, tercia, sexta y nona, así llamadas por las horas del día; vísperas, después de la puesta del sol, y se añadieron después las completas. DiDERot y D'ALEmBert, etc., Encyclopédie, ou dictionnaire raisonné des sciences, des arts et des métiers (1751-1771), París, Librairie Le Breton, t. II, pág. 414.

35 Estos datos fueron facilitados a la comunidad de Santa María por la autora en busca de algún ejemplar.

36 E. García de Pesquera, Beatriz de Silva y Meneses. De dama de la Corte a portaestandarte de la Inmaculada, Madrid, ed. Centro de Propaganda, D. L., 1993. Vid. González Sánchez, Isabel la Católica y su fama de santidad. ¿Mito o realidad?, Madrid, ed. Internacionales Universitarias, 1999. 
El que llamamos Breviario romano, no era el antiguo breviario de la iglesia de Roma, sino un breviario que los Franciscanos (cordeliers) recitaban en la capilla del papa, y que Sixto IV adoptó. El de los franciscanos, orden a la que las concepcionistas pertenecían, y de los jesuitas era el mismo que el romano, con la excepción de algunas fiestas propias y particulares de cada orden ${ }^{37}$. Desconozco qué edición poseyó María Gertrudis en su celda, pero desde la Edad Media el embellecimiento del libro litúrgico no sólo se circunscribía al texto. La suntuosidad de algunas encuadernaciones, ornadas de placa de marfil o de alguna orfebrería, se ofrecían a Dios con el deseo de celebrar la liturgia con magnificencia. Quizás tuviese una de estas ediciones de calidad, quizás no, pero lo cierto era que la orden concepcionista participó de las primeras en la constitución de este libro de rezo. Desgraciadamente, no quedaba rastro de ejemplar alguno anterior al siglo xx en el monasterio de Santa María. En uno de los breviarios conservado hoy en la biblioteca conventual, y según las explicaciones de sor María Luz Suárez, tras el asalto sufrido en los años 1931 y 1936, no quedó ninguno a salvo. Sin embargo, gracias a la solidaridad entre comunidades y a sus relaciones con sus hermanas de Bélgica, al tanto de las desgracias vividas, estas les mandaron uno para remediar la falta tan cruel en una congregación históricamente apegada al ritual litúrgico del rezo ${ }^{38}$.

De los dos juegos de breviarios que poseía María Gertrudis, uno era diurno, es decir sin el oficio de maitines, quizás, porque en el convento de Santa María este oficio nocturno era motivo de fuertes discordias en el seno de la comunidad: pocas parecían dispuestas a las plegarias de noche, razón por la que se rezaban seguidas las vísperas a fines del setecientos, pese a las amonestaciones de los superiores $^{39}$

Poseía también octavarios, libros en los que se apuntaban las fiestas que se celebraban durante ocho días en las que, en su mayoría, se repetía el oficio como los himnos, antífonas, versículos, y maitines a los que, habitualmente, se añadía una lección en relación con dicha fiesta. Siendo monja concepcionista, las octavas de la Concepción y de la Asunción no podían faltar, como tampoco la

37 Diderot y D'Alembert, loc. cit, t. II, págs. 414-415. El discurso de los enciclopedistas es muy parecido al recopilado en el Diccionario del francés Luis Moreri a mediados del siglo XVII. Luis Moreri, Diccionario..., t. II, pág. 467.

38 En la portada estaba escrito: «Donado a nuestra comunidad por nuestras hermanas de Nivelles, el 16 de noviembre de 1937. Concepcionistas Franciscanas de Santa María. Cádiz». Liber Usualis Missae et Officii pro dominicis et Festis cum Cantu Gregoriano ex editiones Vaticana Adamussim Excerpto et rhytmicis signis in subsidium cantorum a solesmensibus monachis, Desclés, Parisiis, Tronaci, Romae, 1936.

39 Un informe redactado por sor Gertrudis al obispo fray Antonio Martínez de la Plaza en la década de 1790 ofrecía esa información de carácter interno: «Que el abuso de los Maitines no lo toque en el escrutinio porque es punto más terrible aquí que el del Refectorio [...]». ADC, Despacho de los Obispos, fray Antonio Martínez de la Plaza, leg. 45, s. n. Carta escrita por MG de la CH. 
de Navidad, de Pascua, Pentecostés, etcétera. Si hablamos de rezo, no podíamos olvidar el canto, ni la música. En el Octavario, habitualmente, el oficio era semidoble, excepto el octavo y último día de la octava en el que el oficio era doble, lo que los Italianos nombraban variazioni en música ${ }^{40}$.

Ya teníamos mayor idea de sus primeros libros, los más valiosos para una religiosa de clausura, así como el esbozo de los mismos, aunque no sepamos ni la edición ni la fecha de publicación de dichos libros. Además de poseer esta lista, tenía información sobre el paradero de algunos. Precisamente, uno de los juegos de breviarios salió de la clausura y fue entregado, según sus voluntades, a Juan María Fleming, familiar de su esposo con el que conservó relaciones tras su ingreso en la clausura. Ignoraba si fue el hermano o el primo de su esposo, por carecer el inventario de segundo apellido, Geynan o Macnamara (el primo). Fuese el hermano o fuese el primo, Juan María Fleming no era ningún desconocido. Destacó por su pensamiento altruista, su tolerancia y humanidad, al traducir la conocida obra de Howard sobre las prisiones en Inglaterra ${ }^{41}$. Una traducción en francés de la obra, cuya autoría se le atribuye, iba a ser el punto de arranque de un moderno sistema penitenciario inspirado sin duda por las ideas del excelente Cesare Beccaria ${ }^{42}$. Juan María Fleming fue capellán de la cárcel del Puerto de Santa María durante muchos años y, probablemente, le fuera fácil visitar a María Gertrudis en Cádiz. Cuando me preguntaba si estuvo en posesión de una bonita edición del breviario, tal vez fue la que entregó a su pariente político porque el precio del segundo juego no dejaba presagiar edición de calidad: «lo ha tomado la novicia D.a María Dolores Rodríguez con los Semaneros en 9 p’ recibido a cuenta 20 r.s., y destinado para misa» ${ }^{43}$.

40 Diderot y D’alembert, Suplemento de la Encyclopédie, t. II, pág. 738. Vid. María Julieta Vega GarCí́A-FERRER, «La música en los conventos de clausura femeninos de Granada», en La clausura femenina en España, actas del simposio I, colección del Instituto Escurialense de Investigaciones Históricas y Artísticas, ed. Escurialenses, 2004, págs. 293-317.

${ }^{41}$ Howard, nacido en Inglaterra en 1726, era el autor del famoso libro sobre las prisiones de su país The State of prisons in England and Wales.

42 Cesare Beccaria, De los delitos y de las penas (introd., notas y trad. de F. Tomás y Valiente), Madrid, ed. Aguilar, 1979 (ed. original, Dei delitti et delle pene, Livourne, verano de 1764). États des prisons, des hôpitaux et des maisons de force II, sec. XVIII, París, 1788. Ver también para Fleming: «Extracto sucinto de la obra de don Juan Howard, sobre el método, dirección y economía de las cárceles, empezada en el año 1774 y concluida en 1783», trad. de Fleming, el cual para su aprobación hubo de recurrir al rey «quien pidió informe en mayo de 1798 al Consejo de Castilla». AHn Estado, leg. 3.238 (exp. núm. 13), el 4 de enero de 1800. Citado por María Luisa Meijide PARdo, Mendicidad, vagancia y prostitución en la España del siglo XVIII. La casa de galera y los departamentos de corrección de mujeres, Madrid, ed. de la Universidad Complutense, 1992, págs. 56 , tesis doctoral ( 2 vols.).

43 María de los Dolores Rodríguez, natural de Cádiz, hija de Francisco Rodríguez y de Manuela Zambón, difuntos, hizo la exploración de la profesión el 9 de diciembre de 1801, con veintitrés años. ACsM, Libro de entradas y profesiones de religiosas de Santa María, ff. 168 v.-169. 


\section{Año Cristiano y la M.e Ágreda no completos}

La revista Año Cristiano fue una obra típicamente dieciochesca, de venta constante de 1753 a 1773, en palabras de Palau. La versión española fue traducida del francés por el padre Juan Francisco de Isla. El título entero, si María Gertrudis poseía algunas de estas versiones, era Año Cristiano, o Ejercicios devotos para todos los Días del año y, según la edición, se componía de once (1771), doce (1773) o dieciocho libros $(1775)^{44}$. Sin embargo, estos datos extraídos de la obra de referencia de Palau no correspondían con los ejemplares que había localizado en la biblioteca conventual.

Atenta a los numerosos volúmenes conservados, catalogando y hojeando cada obra, volví a dar con trece tomos de la primera edición de Benito Cano de la revista Año Cristiano de 1791, además del tomo I del Suplemento de diciembre de 1793 en la imprenta de Joseph García ${ }^{45}$. Esta edición fue traducida del francés al castellano por el Doctor Joaquín Castellot y fue la primera, al menos en la oficina de Benito Cano, publicada en Madrid en 1791. Sólo a partir del tomo V (febrero) la traducción al castellano fue la del padre Joseph Francisco de Isla, como lo sugirió Palau.

Ahora bien, hablar de esta revista sin comentar algo de la escritura de nuestra lectora conventual y, en particular, de su famosa traducción y glosa del texto del Stabat Mater dolorosa publicado en Cádiz en la década de 1790, aunque no me adentraré en su análisis, resultaría de poco provecho. En esta revista localicé la reedición de su traducción y glosa al Stabat, publicada en 1863, más de medio siglo tras su muerte. Si bien es cierto, al consultar las ediciones decimonónicas había comprobado que la organización del Stabat mater compuesto por Gertrudis era idéntica a la estructura utilizada en estas publicaciones (Reflexiones, Meditaciones, Punto primero, Punto Segundo, Propósitos); hasta hace poco, no había tenido la oportunidad de consultar la primera edición en español de finales del siglo XVIII. Me di cuenta de que estas publicaciones estaban compuestas únicamente de textos en prosa, mientras que las del siglo XIX, entrecortaban sus distintas reflexiones con poesías sagradas, tal y como sor Gertrudis había decidido organizar su creación ya a finales del

44 Año Cristiano, o Ejercicios devotos para todos los Domingos, días de Cuaresma y Fiestas movibles del año, trad. del francés por Joaquín Castellot, Madrid, Sancha, Ortega, Aznar, Pérez de Soto, Escribano, Doblado, 1775 (18 vols. en 4. ${ }^{\circ}$ ); Sancha, ed., 1778 (12 vols.), etc. A. Palau y Dulcet, Manual del librero hispano-americano, Barcelona, 2. ${ }^{\text {a }}$ ed., librería Palau, 1951, t. IV, pág. 187.

45 Están los tomos I, II, III, IV y V traducidos del francés (de la obra del padre Jean Croisset) al castellano por el doctor don Joaquín Castellot, y los números de febrero, de abril a julio, de octubre a diciembre traducido al castellano por el padre Joseph Francisco de Isla, catorce tomos en buen estado de conservación. 
setecientos. No obstante, cuál fue mi sorpresa al consultar más detenidamente el tomo III del Año Cristiano publicado en 1791, tomo tercero, el que empezaba desde el Domingo de Pasión hasta el de la Pascua de Resurrección: en el apartado Viernes de la semana de Pasión descubría, algo aturdida, la glosa al Stabat con sus Reflexiones, Meditaciones, Punto primero, Punto segundo, Propósitos ${ }^{46}$, idénticos o casi idénticos a los publicados por la Madre Cruz: al leer los puntos primero y segundo de su Meditación «De los Dolores de la Santísima Virgen» no encontré variaciones algunas entre los dos textos; sin embargo, en el punto dos de sus Propósitos pude apreciar, a mi juicio, algunas correcciones hechas por María Gertrudis.

El erudito gaditano Sebastián Martínez, como sor Gertrudis en su celda o Pulciani en su biblioteca, poseían la revista Año Cristiano del padre Jean Croisset ${ }^{47}$, aunque ella no lo tuviera completo, tal y como lo descubrí en «su» monasterio. Me parecía difícil pensar que este tercer tomo, que tuve el privilegio de manejar en la mismísima clausura, no fuera el que utilizó la gaditana para componer esta creación cuyo encanto, he de decirlo, acababa de desvanecerse en un instante. Mi primer pensamiento fue que María Gertrudis había sencillamente copiado las ocho páginas del texto en prosa de esta publicación madrileña que ella sabía de difícil adquisición, tanto por el escaso número de lectores (aunque tal vez no tanto en Cádiz) como por el precio de estos libros de pasta buena.

Me gustaría desvelar algo que todavía no me había atrevido a interpretar, por la incertidumbre y dilema de su razón de ser: en cada uno de estos catorce tomos, en la portada, venía sellado con tinta un nombre, el de Guillermo Smith como si fuese él el propietario de los libros. Al hojear los tomos, en uno encontré un papelito fechado en Cádiz a 4 de marzo de 1896; en él se confirmaba, para el día 8, una reunión de la Junta General de Celadoras del Rosario Perpetuo en la iglesia de Santo Domingo, cuyo director era Guillermo Smith y Quirós. Quizás estos libros estuviesen, en aquella época, fuera de la clausura. Todavía era demasiado pronto para proponer una explicación convincente. Sin embargo, localicé, en otro libro conservado en la biblioteca conventual, otro nombre escrito con pluma en la portada, el de Adelina Medina, más conocida en Cádiz como La gitanilla del Carmelo, una mujer que fue cercana a las monjas de Santa María.

46 Año Cristiano o ejercicios devotos para todos los domingos, día de Cuaresma y fiestas móviles del año, t. III, 1791, págs. 112-120.

47 A. García-Barquero González, Libro y cultura burguesa en Cádiz: La biblioteca de Sebastián Martínez, Cádiz, 1988, págs. 45-46 y 49. Las obras de J. Croisset fueron muy leídas en su tiempo; Pulciani poseía, además del Año Cristiano, Las Dominicas, Los Ejercicios y el Libro de las Ilusiones del Corazón del padre Jean Croisset. Citado por María Nélida García Fernández, loc. cit., pág. 106. 
Al lado de ese famoso nombre con pluma, venía escrito con lápiz el nombre de Delia Smith.

A mi parecer, estos tomos pudieron pertenecer a María Gertrudis, salir del convento tras su muerte e ir a parar a manos de este hombre de origen inglés, o de sus predecesores, para volver a entrar décadas más tarde en la clausura, tal vez porque Delia Smith, heredera de Guillermo Smith, fuese monja en el convento de Santa María. A no ser que estos catorce tomos en buen estado de conservación fueran devueltos al monasterio por alguien que supiera de la existencia de su primera propietaria. No tenía ninguna certeza, pero sí pistas que había de tener en cuenta por si aparecieran nuevos elementos.

El título Año Cristiano «no completos» en el inventario apareció con el nombre de la Madre Ágreda. Su fama me permitió deducir fácilmente la referencia de este libro sacado a la luz en 1670 en Madrid, cinco años tras la muerte de su autora, con el título: Mística Ciudad de Dios. Milagros de su omnipotencia, y Abismo de la Gracia, Historia Divina, \&c. Esta obra de la mística española fue muy polémica hasta bien entrado el siglo XVIII. Su autora, María Coronel, monja concepcionista en la ciudad de Ágreda, ocupó gran parte de su tiempo en escribir varios tratados místicos que sirvieron al padre Sarmiento para publicar la primera edición de esa famosa obra ${ }^{48}$. Al igual que Isabel de Villena (1430-1490), monja clarisa, la Madre Ágreda compuso una verdadera Vita Mariae, cuya protagonista era la Virgen María ${ }^{49}$.

Pese al éxito, algunos calificaron a la autora de iluminada; otros, considerando sus conocimientos desequilibrados, la tildaron de extravagante. Hubo otra edición en Lisboa en 1681 (3 vols.) y otra en Perpiñán en 1684 (6 vols. $)^{50}$, pese al decreto de la Inquisición de Roma reclamado por los Dominicos, dado a 26 de junio de 1681 por el papa Inocencio $\mathrm{XI}^{51}$. Al traducirse la obra en francés, se levantó el clamoreo: Bossuet, a pesar de tener a la autora como impía, arremetió enérgico contra la sentencia dictada por la Sorbona. El embajador de España en Roma solicitó en vano la revocación del decreto. Si Bossuet calificó la Mística ciudad de impertinencia impía, otro destacado escritor la

48 El librero barcelonés Juan Batista Batlle anunció la publicación de un ejemplar en 1668, pero sin precisar el lugar de edición. Por tanto, Palau consideró que la primera edición fue publicada en Madrid en 1670 por Bernardo de Villa-Diego (3 vols.) (639 págs.). Antonio Palau y Dulcet, loc. cit., t. I, pág. 93. En el inventario de Vicente Pulciani aparecieron dos ejemplares de esta obra escrita por la más famosa de las concepcionistas (cuatro volúmenes en $8 .^{\circ}$ del siglo XVII o XVIII y tres en folio), un libro imprescindible en todas las bibliotecas ilustradas. María Nélida García Fernández, loc. cit., pág. 259.

49 María del Mar Graña Cid, «La Inmaculada Concepción de María y la teología feminista hispana en el renacimiento», en Actas del 150 Aniversario de la Proclamación Dogmática de la Inmaculada Concepción, Toledo, 6-9 de septiembre 2004, Madrid, ed. Cisneros, 2005, págs. 116-117.

50 Diderot y D'Alembert, loc. cit., t. I, pág. 772.

51 Luis Moreri, loc. cit., t. I, págs. 196-197. 
proclamó como burla épica de los Evangelios, y la generalidad de los críticos señalaban pasajes del texto declaradamente pornográficos. La censura de la Sorbona trascendió en España, donde fue temporalmente prohibida su lectura. Por fin, revisada la traducción, la obra se difundió y obtuvo el favor de muchos conventos. Finalmente, el permiso para la impresión en Roma fue acordado hacia mayo de 1729. En total, hubo más de quince ediciones a lo largo del siglo XVIII publicadas entre Madrid y Amberes; ediciones de mayor o menor calidad, todas entre tres y ocho volúmenes (cada volumen unas quinientas páginas $)^{52}$.

Actualmente, en la biblioteca conventual, se conservan varios ejemplares y, tal vez, algunos pertenecieron a María Gertrudis: si no este libro de pergamino de gran tamaño en mal estado publicado en el año 1744 (Libro VII, primero de la tercera parte), quizás, los volúmenes en $4 .^{\circ}$, incompletos, publicados dos de ellos en 1750 (Libro I de la primera parte y Libro VII de la tercera parte) cuyo estado de conservación era envidiable. Existía un cuarto ejemplar en $4 .^{\circ}$ de la Mística ciudad de Dios de esta famosa concepcionista confidente del monarca Felipe IV, editado en 1762 (Libro I de la primera parte) en el que aparecía una «M» escrita con pluma en la portada de esta última edición. Al contrario de las otras versiones, esta empezaba en latín.

Por tanto, como se precisaba en el inventario de la poetisa, no se conservaba en la biblioteca del monasterio ninguna edición completa de esta obra polémica editada en el siglo XVIII, pero sí una del siglo XIX: siete tomos en buen estado de conservación publicados en 1860, adquiridos el 3 de agosto de 1863 por la religiosa sor María de la Paz Hidalgo de Quesada.

\section{Padre Calino y la Religiosa Instruida}

En la lista, venían juntos el «P.e Calino y la Religiosa Instruida», o sea, el nombre de un autor y el título de una obra. Vemos, primero, el apellido del eclesiástico. Tras una detenida búsqueda, pensé que podría tratarse de un libro del padre César Calino, traducido del italiano al castellano por la M. sor María de Córdoba y Pacheco, titulado: Discursos espirituales y morales, para el útil entretenimiento de las monjas y de las sagradas vírgenes que se retiran del siglo

52 Antonio Palau y Dulcet, loc. cit., t. I, págs. 93-95. A lo largo de tres siglos hubo por lo menos noventa y tres ediciones completas y sesenta y ocho abreviadas. Vid. José Antonio Pérez Rioja, «Proyección de la Venerable María de Ágreda (ensayo para una bibliografía de fuentes impresas)», en Celtiberia, núm. 29, 1965, págs. 71-122. 
dirigidos principalmente a las jóvenes, que habiendo de elegir estado, tienen algún pensamiento de ser religiosas.

María de Córdoba tampoco era ninguna desconocida. La profesora LópezCordón tachó la religiosa de «traductora fallida » ${ }^{53}$. No contó con que, decididamente resuelta a llevar a bien aquella traducción, la monja insistió en su empeño. Tras un primer rechazo de los censores, el 18 de marzo de 1785, el Consejo le devolvió la obra "para que la ponga sin enmiendas y en letras que pueda leerse». En un principio, se le había denegado la solicitud de impresión, es cierto; sin embargo, una vez copiado el libro en buena letra, se le concedió la licencia que pedía el 27 de septiembre de $1786^{54}$. La que fue abadesa del convento de religiosas franciscanas de Nuestra Señora de la Paz en Málaga consiguió publicar en su ciudad esta obra que dedicó a su sobrina doña María de Córdoba y Pacheco, hija de los Excelentísimos Señores Marqueses del Vado y de la Sirgadas, Condes de la Puebla del Maestre, Grandes de España. Por la cercanía de la toma de hábito de su «querida sobrina», esa mujer no podía resignarse al fracaso. Quería que su pariente conociera las instrucciones del padre Calino; sólo le hizo prometer que se aplicase: «a leer con la mayor reflexión estos Libros, que te dedico con el único fin de que saques de ellos la espiritual utilidad, que te desea tu amantísima Tía ${ }^{55}$. La obra se componía de tres tomos en $4 .{ }^{\circ}$, aunque la traductora precisara que estaba traduciendo la cuarta parte. Asimismo, eludió hábilmente, conformándose con los cánones intelectuales exigidos a las mujeres, las futuras críticas al afirmar a su sobrina: «no pierdas el tiempo en criticar a quien llanamente te confiesa la cortedad de sus luces, e instrucción en la materia». Una obra, como muchas otras de esa naturaleza, dividida en discursos, cuyo primer alegato trataba de las «Ventajas del claustro».

Si María Gertrudis entró con algunos libros en la clausura, lo más probable era que adquiriese otros a lo largo de su monacato. Si consideramos la fecha de publicación, 1786, de esa obra traducida, no quedaba duda sobre la compra de libros estando profesa. A no ser que lo leyera en su versión original, cuya fecha de publicación ignoraba. De todas formas, al preguntarme cómo se le había ocurrido adquirir este libro, cómo había tenido noticia de su impresión, tal vez, tenía algún elemento de respuesta en el «Prólogo de la traductora»:

\footnotetext{
53 V. M. LóPEZ-CoRdón, «Traducciones y traductoras en la España de finales del siglo XVIII», art. cit., págs. 107-108.

54 Citado por M. Serrano y Sanz, Apuntes para una biblioteca de escritoras españolas..., t. I, págs. 280-281.

55 Dedicatoria de la autora sor María DE CÓRDOBA Y PACHECO (trad.), Discursos espirituales y morales, para útil entretenimiento de las Monjas, y de las Sagradas Vírgenes, que se retiran del siglo. Dirigida principalmente a las Jóvenes, que habiendo de elegir Estado, tienen algún pensamiento de ser Religiosas, escritos en italiano por el padre César Calino, parte I, Málaga, en la Imprenta y Librería de D. Félix de Casas y Martínez, 1786.
} 
Habiendo merecido al favor de Sr. Dr. Antonio Guerrero y Aranda, (al presente Deán y Canónigo de la Sta. Iglesia Catedral de Cádiz) la obra de Cesar Calino, le debí igualmente la fineza de darme una ligera instrucción del Idioma Italiano, para que pudiera aprovecharme de su excelente doctrina ${ }^{56}$.

El propio deán de Cádiz, el Dr. Antonio Guerrero, el que había asistido a la profesión de la Hija del Sol ${ }^{57}$, había propugnado a la traductora cordobesa alguna lección de italiano. Sin duda, ese eclesiástico comentó a Gertrudis, y/o a su comunidad, los beneficios espirituales de la lectura de este texto.

Hecho curioso, el autor reveló a las religiosas no tener práctica de monasterios, no haber oído nunca confesiones de monjas, ni haber tratado con ellas. Sin embargo, en su primer discurso, aparecía un verdadero requisito a favor de la vida claustral, a la vez que denunciaba las calamidades que esperaban a las jóvenes si decidían quedarse en el siglo. Para convencer de las ventajas del claustro, el autor pintaba todas las desgracias femeninas infundiendo temores, hasta escalofríos:

¿Qué deberá decirse de las largas incomodidades de una preñez? [...] ¡Qué dolores de parto, siempre llenos de temor, aun cuando la Madre se desembarace con toda felicidad! [...] Con multiplicarse los hijos, se acrecientan las fatigas, los cría con solicitud, después de crecidos, los mira con amargura; mientras son pequeños son molestos; cuando crecidos, serán ingratos ${ }^{58}$.

El discurso de este eclesiástico, en boca de su traductora, desvanecía toda pretensión matrimonial y evidenciaba una realidad a la que la propia Gertrudis tuvo que enfrentarse al casarse con el nuevo socio de su padre ${ }^{59}:$ «No es pequeño tormento querer esposo, y no poderle escoger a gusto. ¿Quien le ha de sufrir?

56 «Prólogo de la traductora», en Discursos espirituales y morales, para útil entretenimiento de las monjas..., s. p.

57 Manuel Serrano y Sanz, loc. cit., pág. 527.

58 Ibid., págs. 13-15.

59 No se presentó, como de costumbre, a la redacción del capital de su esposo, sino sólo sus padres. María Gertrudis prefirió quedarse en casa ese día 29 de diciembre de 1763 y no hacer acto de presencia en el estudio del notario. Tal vez fuera el signo de su descontento, de sus primeras reticencias hacia ese matrimonio de conveniencia, o tal vez no. La desaparición de su expediente matrimonial, calificado de «valiente» por el antiguo director del Archivo Diocesano, no me ha permitido aportar más precisiones. Según Paloma Fernández, los expedientes matrimoniales del obispado no solían incluir los testimonios y pormenores de las razones invocadas para la obtención de las dispensas. Por tanto, ¿por qué calificar de «valiente» ese expediente si no recogía nada de importancia? AHPC, n. 5, PT 1040, ff. 647-649. Francisco Toscano DE Puelles, «El Archivo Diocesano de Cádiz como fuente histórica», en Hidalguía, CSIC, Madrid, 1971, pág. 16. Vid. Paloma FERnándEZ PÉREZ, El rostro familiar de la metrópoli. Redes de parentesco y lazos mercantiles en Cádiz, 1700-1812, Madrid, Siglo XXI de España Editores, S. A., octubre de 1997, pág. 99. 
[...] Que una Joven elija por sí misma el Esposo, se recibe como un delito: que proponiéndosele, lo desprecie, se calumnia como una injuria [...]» ${ }^{60}$.

En los discursos siguientes, a partir de personajes de la Biblia, la traductora comentó las diferentes vocaciones, insinuada (por los padres), de empeño (por afecto), divina (la más perfecta) e impedida, así como las distintas etapas que ritmaban la vida religiosa (noviciado, mutación del nombre...) y los oficios de cada una según la jerarquía monástica (Abadesa, Vicaria, Provisora, Maestra de Novicias, Maestra de las Educandas, Sacristana, Porteras y Torneras, Escuchas, Enfermeras, Discretas, Organistas y Cantoras). Pese a que estuviese exclusivamente dirigido a las religiosas o futuras religiosas, ese manual ofrecía amplios fundamentos de la vida civil a finales del setecientos; con la mayor convicción, se denunciaba la situación fatigosa de las mujeres ante tantas obligaciones sociales, aconsejando a la joven tomar el velo y librarse así de tormentos.

Además de optar por esta obra del padre Calino, y no por otra ${ }^{61}$, al intentar desenmarañar su lista de libros, me parecía adaptarse mejor al título con el que estaba asociado: La religiosa instruida. Ese tratado de moral religiosa estaba escrito bajo la forma del diálogo familiar entre un director espiritual y su discípula. Los diálogos estaban dirigidos igualmente a religiosas como a religiosos, a personas devotas y a todos los que querían servir a Dios y llegar a la perfección de sus estados; pero la única motivación de su autor, un carmelita descalzo francés, fue «la salvación de las religiosas» ${ }^{62}$. Destacó la existencia de «tantos libros, para dirigir y gobernar a los confesores», y la escasez de los que servían para

[...] gobernar y dirigir a una muchedumbre casi innumerable de Religiosas, que se hallan oprimidas de penas, y de dudas, de tentaciones, y de escrúpulos, de remordimientos y temores, sin saber las más veces, [...] a quien acudir, para remediar sus aflicciones.

En un primer momento, el director y la religiosa, con un tono muy cortés, se saludan. Este le trae una misiva en la que espera noticias de la salud de su madre.

60 Discursos espirituales..., págs. 7-10.

${ }_{61}$ Sus Lecciones teológico-morales sobre el juego, a mi juicio, nos alejaban de las lecturas habituales en la clausura femenina. El juego estaba prohibido a las mujeres, no podían acceder a salas de truco u otras reuniones lúdicas muy de moda en el siglo XVIII. P. César CALIno, Lecciones teológico-morales sobre el juego, trad. del toscano al castellano por don Francisco Collar (P. Antón Mourin) en Madrid, Juan de Zúñiga, 1737, en $4 .^{\circ}$ (400 págs.). A. Palau y Dulcet, loc. cit., t. III, pág. 58.

62 Fray José Quiles (trad.), La religiosa instruida y dirigida en todos los estados de la vida, con diálogos familiares obra muy útil no sólo para las religiosas, sino también para los religiosos, personas devotas y todos los fieles que quieren servir a Dios con celo, y llegar a la perfección de sus estados, escrita en francés por un religioso carmelita descalzo, Imprenta de Ruiz, Madrid, 1805, pág. 1. 
Empero, rápidamente, el director desconfía y evoca episodios de los Evangelios para alegar su aprensión, poniendo en boca de la religiosa las mayores ligerezas y defectos en el comportamiento:

En la celda me fastidio y para divertirme voy a ver a una Religiosa joven que me estima mucho, y a quien tiernamente amo, y allí hablamos de los negocios del Convento, o de nuestras familias [...] hablamos de las Religiosas del Monasterio, y decimos todo cuanto sabemos de ellas ${ }^{63}$.

Escenas perfectamente creíbles a finales del setecientos, si no en todos los monasterios, al menos en algunos:

Tomamos el chocolate y conversamos [...] Cuando [...] oigo llamar a las Religiosas, [...] muchas veces me obliga la curiosidad a preguntar a la tornera, a qué Religiosa llaman, y quién la llama. Si soy yo la llamada estoy muy contenta, y luego me compongo y preparo para acudir lo más pronto ${ }^{64}$.

El eclesiástico pretendía enseñar a las monjas cómo comportarse en la clausura, «estando retirada en vuestra celda, ocupada en leer, trabajar o meditar la Ley de nuestro Dios» ${ }^{65}$. Infundía temor, el temor de Dios, el miedo a la salvación, invitaba a la mortificación y aconsejaba la frecuente confesión para luchar contra los vicios. En su segunda parte, hablaba de la Gracia, de la Esperanza, de los dones del Espíritu Santo, de las virtudes cardinales (prudencia, justicia, fuerza y templanza), de la obediencia, de la pobreza, de la castidad, valores, virtudes y dones esenciales a la buena educación de las religiosas, ofreciendo al público monjil un auténtico manual de comportamiento.

María Gertrudis leyó probablemente la edición de 1776, únicamente dirigida al clero y escrita por fray Antonio Arbiol, un autor muy estudiado en el siglo XVIII, cuyos ejemplares de pergamino ocupan hoy los estantes de la biblioteca conventual de los dos monasterios concepcionistas de Cádiz ${ }^{66}$.

En el de Santa María, permanecía con tapa de pergamino una edición de 1753 en buen estado de conservación: La Religiosa Instruida con doctrina de la sagrada escritura [...] para todas las operaciones de su vida regular, desde

${ }^{63} \quad$ Ibid., pág. 6 .

64 Ibid.

65 Ibid, pág. 8.

66 En la Biblioteca del Monasterio de la Piedad se conservaban dos ejemplares de la Religiosa Instruida de Antonio Arbiol, una edición publicada en Zaragoza y la otra en Madrid (1. as eds. los dos). Según las explicaciones de sor Nieves, la bibliotecaria, con el beneplácito de madre Benita García García, la abadesa. 
que recibe el hábito santo, hasta la hora de su muerte, publicada en Madrid en la imprenta de la causa de la V. M. María de Jesús de Ágreda, y otra de 1765 publicada por Juan de San Martín. Esta última, al menos a finales del siglo XIX, formaba parte de la biblioteca conventual: en la portada, la madre Clara había escrito en el interior del volumen «Correcturia», o sea, biblioteca, según las explicaciones de sor María Luz Suárez.

\section{Introducción a la Vida Devota por San Francisco de Sales}

Introducción a la Vida Devota por S.n Fran.co de Sales era el único título completo del inventario, aunque no tuviera lugar de edición, ni fecha. Este libro ofrecía una dirección clara de su forma de entender y practicar la fe. San Francisco de Sales (1567-1622) fue uno de los primeros grandes autores espirituales de lengua francesa, y uno de los más importantes de la época moderna; participó en la renovación espiritual de los católicos en una época en la que la mayoría estaba lejos de responder a las exigencias de su misión. Predicó, confesó, visitó los conventos y se preocupó por la reforma de estas casas. Propuso algunas actitudes concretas, exteriores e interiores, que hacían la perfección compatible con las exigencias de la vida ordinaria. Su penetración, su humanismo, sacrificando parte de la austeridad del cristianismo, le fueron reprochados por sus contemporáneos. Su originalidad residía en considerar y adaptar su dirección espiritual a cada caso, promocionando la individualidad, el análisis interior verdadero, o sea, cierto psicologismo en la espiritualidad cristiana. Su formación humanista le invitaba a creer en la capacidad de regeneración del ser humano. Según él, el alma llegaba a un estado de «santa indiferencia» y renunciación a todo deseo; esta «santa indiferencia» afectaba tanto la vida exterior como el desarrollo de la vida interior. Sin embargo, la filosofía del santo estaba lejos del misticismo de San Juan de la Cruz y, al parecer, sor Gertrudis compartió su visión, así como la de sus discípulos. En la biblioteca conventual permanecían varios ejemplares: dos editados a finales del siglo XVIII, uno a costa de Bartolomé de Ulloa, y otro en Barcelona ${ }^{67}$.

67 Francisco de Cubillas Donyague, Introducción a la vida devota de San Francisco de Sales, ahora nuevamente corregida, y enmendada por el original francés con una declaración mística de los cantares de Salomón para tener oración mental y con el directorio de religiosas que se añade en esta última impresión a costa de Bartolomé de Ulloa, Madrid, Andrés Ortega, 1771. Introducción a la vida devota de San Francisco de Sales [...], con el directorio de religiosas que sale mejor corregido en esta última impresión dedicado a Santa Gertrudis la Grande, en Barcelona, en la imprenta de Pedro Escuder, a costa de Pablo Campins: Véndense en su casa, a la calle de Amargos. s. f. 
VII. Triunfo de la Religión y la fundación de las Monjas de Mula

La penúltima referencia de esta lista, Triunfo de la Religión me resultó mucho más conflictiva a la hora de decidir a qué obra se refería. Tampoco me fue fácil descifrar, en un principio, qué título se escondía tras la fundación de las Monjas de Mula. En cuanto a la primera, por su título de carácter general, me resultó casi imposible decidirme por alguna. En un primer momento, pensé en las cartas (cinco vols. en $4 .^{\circ}$ ) traducidas del francés por el P. Clemente Millana, Triunfos de la verdadera Religión, contra los extravíos de la Razón, entre 1792 y 1793, cuyo título original era Le Comte de Valmont, ou les égarements de la raison del P. E. Gérard. Sin embargo, por el contenido de las cartas y su carácter contrarrevolucionario (aunque fuese compartido por la poetisa) ${ }^{68}$, así como por el plural del título, me decidí por otros títulos. En particular, por el libro del cardenal Vincenzo Ludovico Gotti, cuyo largo título incluía el término Triunfo de la verdadera Religión, seis volúmenes en $4 .^{\circ}$ publicados a mediados del setecientos ${ }^{69}$. Había también obras de teatro con ese título, como la de François-Thomas-Marie de Bacular d'Arnaud (1718-1805), Eufemia o el triunfo de la religión ${ }^{70}$; obrita de música ${ }^{71}$, obras en italiano en su mayoría como Trionfo della Religión cristiana por Francesco Marescandoli ${ }^{72}$. No tenía prueba científica alguna para poder elegir una de estas obras, podría ser cualquiera de estas, o bien ninguna ${ }^{73}$.

La fundación de las Monjas de Mula, cuyo verdadero título estaba lejos de lo apuntado en el inventario por sor Bosichi, dejaba presagiar que esta monja

68 María Gertrudis tradujo del italiano un soneto dirigido a Voltaire en el que denigraba los pensamientos del filósofo y le culpaba de todos los males sufridos durante la Revolución Francesa. BNM, ms. 4061, f. 255.

69 Cardenal Vincenzo Ludovico GotтI, La verdadera Iglesia de Cristo, demostrada con señales y dogmas, contra los dos libros de Jacob Picenino intitulados: Apología por los Reformadores, y por la Religión reformada y Triunfo de la verdadera Religión obras escrita en italiano, trad. al español por el M. R. P. M. Fr. Julián Sainz, Madrid, Oficina de Joaquín Ibarra, 1758-68. (6 vols. en 4. ${ }^{\circ}$ ); otro texto en acuerdo con la orden a la que pertenecía la poetisa: fray Gregorio PANGHELIA, Relación verdadera del celebérrimo triunfo de la Religión Franciscana, recuperando los Santos Lugares de Jerusalén, Madrid, Juan García Infançon, s. a. (20 págs. en 4. ${ }^{\text {). }}$.

70 François-Thomas-Marie de Bacular D’Arnaud, Eufemia o el triunfo de la religión. Drama dividido en tres actos. Traducido del francés al castellano, imp. de D. Antonio de Espinosa, Madrid, 1790.

${ }^{71}$ Triunfo de la Religión por la nave de la gracia: oratorio sacro-alegórico por la victoria, que consiguieron las católicas armas contra los turcos en el golfo de Lepanto, siendo uno de los generales el excelentísimo señor don Luis de Requesens, quien logró de la Santidad de Pío V indulgencia plenarias [...] para los que [...] visitaren su Iglesia de Nuestra Sra. del Palao de Barcelona el día 7 de octubre, puesto en música por el Sr. Joseph Durán, Maestro de la Real Capilla de la misma Iglesia, y ejecutada por aquella, Imp. Joseph Altès, 1701-1800, Barcelona (seis hojas en $4 .^{\circ}$ ).

72 Francesco Marescandoli, Trionfo della Religión cristiana a confusiones dell'adulazione difenditrice degli Ebrei battezzati apostati, descritto da un Minore Sacerdote, Lucca, 1732. (en 12. ${ }^{\circ}$ ).

73 Es de notar que no aparecía ningún ejemplar con ese título en la Biblioteca del Monasterio de las Descalzas, advocación la Piedad, según me informó sor Nieves. 
conocía el contenido de dichos libros (tres tomos, 1413 páginas) si no, no hubiese resumido así la Crónica del religioso observantísimo del Real Monasterio de María Santísima de la Encarnación, religiosas franciscanas descalzas de la villa de Mula, de Fr. Ángel Molina y Castro ${ }^{74}$. Una obra cuya dedicatoria, en «La Purísima Concepción de Mula», estaba fechada a 28 de diciembre de 1777, o sea, muy poco antes de que sor Gertrudis tomase el velo. La publicación celebraba sus cien años de fundación, "y cien Religiosas que en ellos han recibido el santo velo», en su mayoría monjas de noble ascendencia ${ }^{75}$.

El libro era verdaderamente digno de elogio. Relataba la historia del monasterio con el mayor rigor científico, según lo anunciaba su autor en el prólogo: «he consumido mucho tiempo en investigar documentos, y aplicado toda mi reflexión para examinar en su lección la verdad», aunque no desvelase todas sus fuentes. Narraba la antigüedad de su fundación en la famosa ermita de Santa María de los Olmos, así como su situación en Mula, primera villa del reino de Murcia; la procedencia de las religiosas, las circunstancias del viaje de Trujillo a la corte, llamadas por el monarca al tanto de la santidad de sus fundadoras; el viaje de Madrid a Mula, su hospicio, recibimiento, posesión y la toma de hábito de las diez señoras alistadas así como la fundación material del convento en la ermita, la estrechez del hospicio y la cortedad de sus medios. Estos tres tomos no eran sólo el relato de las disciplinas prolongadas y vigorosas de la madre Mariana de Santa Clara, primera fundadora y abadesa, sino mucho más: se hablaba de la vida de sor Juana de la Cruz, segunda fundadora, de la vida de las monjas, de las elecciones canónicas de las abadesas sucesivas, etcétera.

Además de la inscripción de este libro en el inventario de su celda, la localización de varias cartas de hermandades entre comunidades me permitía afirmar la cercanía de los dos conventos desde tiempos remotos. Probablemente, tras la lectura de estos tres tomos, la comunidad de Santa María de Cádiz quiso estrechar vínculos de fraternidad espiritual con las Descalzas de Mula. Por ello, redactaron con pluma en pliego doble de pergamino, un compromiso de hermandad a primero de julio de 1802, la más antigua carta de hermandad conservada hoy en el Archivo conventual ${ }^{76}$. En el original, se podía apreciar la demanda

74 Fr. Ángel de Molina y Castro, Crónica del religioso, observantísimo Real Monasterio de María Santísima de la Encarnación, religiosas franciscas descalzas de la primera regla de nuestra Seráfica Madre Santa Clara, fundado en la Ilustre, Noble, y Antigua villa de Mula, diócesis de Cartagena, reino de Murcia, Felipe Teruel, s. a. El ilustrado gaditano Pulciani poseía estos libros en su biblioteca. María Nélida García FernándEz, loc. cit., pág. 106.

75 Fr. Ángel de Molina y Castro, loc. cit., s. p. (prólogo).

76 Siendo abadesa del convento de Mula, sor Francisca María de Santa Ana, y de Cádiz sor Bárbara de la Santísima Concepción Morejón. El monasterio de las Descalzas, advocación la Piedad, no poseía ningún ejemplar de este libro, sino sólo una Crónica del religioso observantísimo del Real Monasterio de María Santí- 
de la abadesa de Santa María de Cádiz y su comunidad «por su gran devoción» en hacer partícipe «dicha S.ra Abadesa y S.ta Comunidad de todas nuestras oraciones y ejercicios espirituales como si se hallasen presentes a cada uno de ellos»; y, particularmente, cuando se moría alguna religiosa, ambas comunidades se obligaban a ofrecer por el alma de la difunta una misa. A partir de entonces, vivieron en recíproca correspondencia pidiendo las unas por las otras en todos sus ejercicios y oraciones como «verdaderas hermanas e hijas de una misma Madre». Sin embargo, en palabras de la madre Clara,

después de muchos años se perdió la memoria de dicha Hermandad hasta que en el de 1894 se encontró en el Archivo la carta de confraternidad lo que se comunicó a aquella Comunidad que también lo ignoraba, y tuvimos mutuamente muy especial gusto en renovar este espiritual contrato ${ }^{77}$.

\section{Varios libros devotos}

Esta última «precisión» inscrita en su inventario post mórtem sólo producía rabia e impotencia. ¿Cuántos había? ¿Cuáles eran? Al examinar cada uno de los libros conservados en la biblioteca conventual editados entre los siglos XVII y XVIII, algunos, por la calidad de su edición, por su temática y/o su autor, hubieran podido pertenecer a María Gertrudis. Pensaba, por ejemplo, en los Ejercicios espirituales que la Madre Ágreda practicó en su convento, un libro en 4. ${ }^{\circ}$ con tapa de cuero, bordado dorado y rojo publicado en $1769^{78}$; o bien en las Cartas espirituales de San Francisco de Sales, publicadas en 1770 divididas en siete libros ${ }^{79}$. Precisamente, en la página interior de la portada de este libro venía escrito: «Libro del uso de la Com.d de RR. de la Purísima Concepción Voc.n Santa María de esta ciudad de Cádiz que dejó la S.a D.a Juana López Religosa del mismo convento a utilidad espiritual de sus HH». La religiosa Juana López y

sima..., lo que más se parecía a la Crónica de los Descalzos de San Francisco de fray Iván Santa María, según las explicaciones de sor Nieves.

77 ACSM, Cuadernito sobre «Hermandades» contratadas con el monasterio de Santa María, f. 19. La abadesa de Santa María era, desde el año 1879, sor María Gertrudis de la Concepción García Arce, y lo fue hasta el año 1898.

78 Ejercicios espirituales de retiro que la venerable Madre de Jesús Ágreda practicó, y dejó escritos a sus hijas para que los practicasen en su Religiosísimo Convento de la Purísima Concepción de la misma villa, Pamplona, 1769.

79 Cartas espirituales de San Francisco de Sales, Primera parte. A costa de Bartolomé Ulloa, se hallará en sus librerías, calle de la Concepción Geronyma, y de Cádiz junto al Pópulo, Madrid, por Andrés Ortega, 1770. 
Perea fue monja en el mismo periodo que María Gertrudis y era de notar que en el interior de este mismo libro venían apuntadas unas palabras poco comprensibles pero escritas por la propia Gertrudis: «C.l o c. del Hurón o Turón N. $52{ }^{80}$. Del mismo autor se conservaban varios títulos y ediciones publicadas en 1770, como los Sermones familiares ${ }^{81}$. Al igual que el libro anterior, en su interior venía escrita la misma frase, o sea, el nombre de Juana López, su antigua propietaria, al que se le añadía «(Que en Paz descanse)» ${ }^{82}$.

Era de extrañar la conservación de tres ediciones sin fecha de La Religiosa en soledad $^{83}$, obra que exponía el modo de emplearse con fruto en los ejercicios espirituales de San Ignacio de Loyola, y su total ausencia en el inventario post mórtem de sor María Gertrudis de la Cruz Hore, con mayor motivo, sabiendo que una de sus correligionarias poseía este libro; en uno de ellos venía escrito: «Este libro es de Nicolasa Rosa de Jesús Nazareno y la Purísima Concepción Río y Pacheco» ${ }^{84}$.

Cómo concebir la ausencia de un autor como San Juan de la Cruz en su biblioteca, en la celda de esta religiosa culta, una ilustrada que escribe. Actualmente, en el monasterio se conservaba una bonita edición, de principios del siglo XVIII, de las Obras espirituales del primer padre de la reforma de nuestra señora del Carmen, y compañero de Santa Teresa de Jesús. La obra, en buen estado de conservación, estaba repleta de grabados preciosos, algunos de Mathias Arteaga fechados a 1701; se recogían las devotas poesías de San Juan, algunos poemas dedicados a religiosas de Córdoba bajo la forma de cartas espirituales, las Noches oscuras del alma, así como La subida al monte Carmelo ${ }^{85}$. Por último,

80 Juana Manuela López y Perea profesó el 16 de abril de 1779 con más de cuarenta años; era natural de Jerez de la Frontera e hija de Joseph López y de María de Perea. La pulcritud de su firma dejaba entrever una educación de calidad. ACSM, Libro de entradas y profesiones de religiosas de Santa María, ff. 136 v. 137.

${ }^{81}$ Sermones familiares compuestos por San Francisco de Sales, tt. I y II, a costa de Bartolomé Ulloa, Madrid, por Andrés Ortega, 1770.

82 Juana López murió el día 22 de agosto de 1788 siendo clavera. ACSM, Libro 10 de las cuentas del año de 1781 a 1789, f. $110 \mathrm{v}$.

83 La Religiosa en soledad, obra en que se expone a las religiosas el modo de emplearse con fruto en los ejercicios espirituales de San Ignacio de Loyola, compuesta en italiano por el P. Juan Pedro Pinamonti de la Compañía de Jesús y traducida en español por el P. Martín Pérez de Culla de la misma Compañía. Añadido en esta última impresión un breve tratado del Árbol de la Vida, excelencias, y frutos del Santo Sacrificio de la Misa dedicada a la soberana reina de los cielos María Santísima Madre de Dios, y Señora Nuestra, Barcelona, en la imprenta de los Herederos de Bartolomé y María Ángela Giralt, administrada por Juan Roger. s. f. La aprobación del texto es de 1700 y hay otra de 1723. Los otros dos fueron publicados en Barcelona, por Jayme Ofset y Carlos Sapera, Libreros, a costa de Francisco Suria, Impresor, y de los dichos.

84 Era natural y vecina de Cádiz, hija de Juan Manuel de los Ríos y de Elvira Pacheco, de estado doncella y de más de cuarenta años cuando profesó el 10 de febrero de 1766. ACSM, Libro de entradas y profesiones de religiosas de Santa María, ff. 85-87.

85 Obras espirituales que encaminan a una alma a la más perfecta unión con Dios en transformación de amor por el extático, y sublime doctor místico el beato padre san Juan de la Cruz, Impresión duodécima, en 
cómo proyectar este espacio monacal, su aposento, sin las obras de Teresa de Jesús, conociendo la fama y el renombre de la Santa Madre, sabiendo que la Hija del Sol, como muchos otros gaditanos, era muy devota de la imagen del Carmen $^{86}$. De hecho, el libro más antiguo conservado en la Biblioteca conventual era, precisamente, las Obras de Santa Teresa, publicadas en los Países Bajos en 1630; el único libro editado en el siglo XVII que conservaba apuntes: al margen del texto venían algunos comentarios y frases subrayadas, muy probablemente, por alguna monja del seiscientos ${ }^{87}$.

Oficialmente, María de la Cruz poseía libros de rezos (breviario), obras de teología mística (M.e Ágreda), historia de fundación de monasterio (Mula), manuales para cenobitas (La religiosa instruida, el P.e Calino), revistas religiosas (Año cristiano), y compartía la filosofía de San Francisco de Sales (Introducción a la vida devota), además de poseer el Gran diccionario histórico de Moreri y otro de lengua castellana.

No obstante, la cultura y erudición de esta original monja de la orden de la Concepción, señalada poetisa gaditana de alcurnia irlandesa, era mucha más amplia, mucho más diversa que estos once títulos de índole religiosa recogidos en su inventario post mórtem. Desafortunadamente, la documentación oficial sólo ofrecía informaciones parciales y fragmentarias de sus lecturas. Sin embargo, tenía ahora la certeza de que la Reina de las Musas había adquirido sólidos conocimientos litúrgicos en el convento de Santa María, aunque demostrase sus competencias bíblicas ya a finales de 1777, muy poco antes de su toma de velo, con la publicación anónima de la Novena al Santo Cristo de la Esperanza ${ }^{88}$.

Sevilla, por Francisco de Leefdael, en la Ballestilla, 1703.

${ }^{86}$ Acordémonos, según el tenor de su inventario post mórtem, tenía una urna de Nuestra Señora del Carmen en su celda, además de otras imágenes religiosas.

87 Las obras de la S. Madre Teresa de Jesús fundadora de la reformación de las descalzas y descalzos de N. Señora del Carmen. Tercera parte que contiene sus fundaciones y visitas religiosas, en Amberes, en la imprenta Plantiniana de Balthasar Moreto, 1630. Obra de la gloriosa Madre Santa Teresa de Jesús... dedicadas al Rey Fernando VI, tt. I y II, Madrid, Imp. del Mercurio por Joseph de Orga, 1752. Dos ejemplares del primer tomo de una edición de 1778 publicada en Madrid en la imprenta de Joseph Doblado. Y Avisos espirituales de Santa Teresa de Jesús comentados por el padre Alonso de Andrade de la Compañía de Jesús, tt. I y II, Barcelona, en casa de Cormellas, por Tomás Loriente, 1700.

88 Se trata de un desconocido librito devoto de cuarenta y ocho páginas, publicado apenas algunos meses antes de su ingreso en el convento. Fue elogiado por el censor y poeta gaditano Cayetano Huarte: subrayó la originalidad del escrito, notó el fervor de la devoción expresada y animó a que se publicara. Una originalidad que, según el eclesiástico, permitiría al género renovarse ante la conocida decadencia de la escritura religiosa durante la segunda mitad del siglo XVIII. Novena al Santo Cristo de la Esperanza que se venera en el Convento de Santa María de la ciudad de Cádiz, compuesta por una Persona devota de esta Venerable Imagen, Cádiz, Manuel Espinosa de los Monteros Impresor de la Real Marina, 1778. 